\title{
DO AIRLINES IN CHAPTER 11 HARM \\ THEIR RIVALS?: BANKRUPTCY AND \\ PRICING BEHAVIOR IN \\ U.S. AIRLINE MARKETS
}

Severin Borenstein

Nancy L. Rose

Working Paper No. 5047

\section{NATIONAL BUREAU OF ECONOMIC RESEARCH 1050 Massachusetts Avenue \\ Cambridge, MA 02138 \\ February 1995}

We thank Robert Gertner for helpful comments, and the National Science Foundation, Alfred P. Sloan Foundation, and Center for Advanced Study in the Behavioral Sciences for financial support. A shortened version of this paper is forthcoming in American Economic Review Papers and Proceedings, May 1995. This paper is part of NBER's research program in Industrial Organization. Any opinions expressed are those of the authors and not those of the National Bureau of Economic Research.

(C) 1995 by Severin Borenstein and Nancy L. Rose. All rights reserved. Short sections of text, not to exceed two paragraphs, may be quoted without explicit permission provided that full credit, including (C) notice, is given to the source. 


\title{
DO AIRLINES IN CHAPTER 11 HARM \\ THEIR RIVALS?: BANKRUPTCY AND \\ PRICING BEHAVIOR IN \\ U.S. AIRLINE MARKETS
}

\begin{abstract}
The behavior of firms in financial distress has attracted considerable academic and policy interest in recent years. The turmoil in the U.S. airline industry has triggered much of the public policy discussion, as some observers have argued that airlines in financial distress, particularly those operating under Chapter 11 bankruptcy protection, reduce prices to the point of harming themselves and their competitors. This study investigates the pricing strategies of bankrupt airlines and their rivals. The data suggest that an airline's prices typically decline somewhat before it files for bankruptcy protection and remain slightly depressed over the subsequent two or three quarters. We find no evidence that competitors of the bankrupt airline lower their prices, however, nor that they lose passengers to their bankrupt rival. These results indicate that bankrupt carriers do not harm the financial health of their competitors.
\end{abstract}

Severin Borenstein

U.C. Energy Institute

2539 Channing Way

Berkeley, CA 94720-5180

and NBER
Nancy L. Rose

Sloan School of Management

MIT

50 Memorial Drive, E52-434

Cambridge, MA 02139

and NBER 
Modern economics has generated many theories of the ways in which a firm's financial condition may affect its conduct in the product market. Though some of these imply that a company constrained by capital structure or financial distress will compete less aggressively, a common view among business people is that a firm in financial trouble has "nothing to lose" and will slash prices to "generate cash." Perhaps nowhere has this view been repeated more often than in the airline industry. Managers at major carriers, as well as a blue-ribbon government task force on the industry's financial woes, have argued that financially weak airlines, and especially those under Chapter 11 bankruptcy protection, have cut prices and harmed the financial health of the industry. ${ }^{1}$

There are a variety of channels through which financial distress, and bankruptcy in particular, might affect pricing decisions of such firms and their rivals. First, filing for bankruptcy protection may directly alter costs or demand for the bankrupt carrier. If bankrupt carriers are able to lower their marginal costs through abrogation of existing labor and equipment lease contracts, then filing for bankruptcy may lower a carrier's pre-

1 The Report of the National Commission to Ensure a Strong Competitive Airline Industry states that "The Commission recognizes that the financial problems facing the airline industry have been caused by a number of factors and that bankrupt carriers have been one of those factors." (p. 15). 
ferred price on a route. Similarly, if passengers perceive a bankrupt carrier to offer lower quality service and consequently reduce their demand for its flights, a bankrupt carrier may want to lower its price. Competing airlines may choose to match these price decreases or not, depending on how lower prices of the bankrupt carrier affect the residual demand facing other airlines. Second, bankruptcy may lead an airline to discount future revenues more heavily. This could imply either higher current prices (as in models with consumer switching costs, where lower current prices can be viewed as an investment in market share that generates higher profits in the future) or lower current prices (as in collusion models, where increases in discount rates may lead to deviations from cooperative pricing behavior). Third, bankruptcy may alter the strategic position of the firm, committing it to more aggressive competition (e.g., by inducing a preference for greater risk) or less aggressive competition (e.g., by increasing liquidity constraints or otherwise constraining managerial actions). Finally, bankruptcy may invite predatory behavior by financially healthy rivals because it may limit the ability of the bankrupt firm to finance a costly price war.

Despite considerable theoretical work, there have been few empirical tests of financial or capital structure effects on prod- 
uct market behavior. ${ }^{2}$ This study contributes to the empirical evidence by reporting the effect of bankruptcy announcements on pricing behavior in the U.S. airline industry. We use data from the seven Chapter 11 bankruptcy filings by large U.S. air carriers between 1989 and 1992: Eastern (March 1989), Braniff (September 1989), Continental (December 1990), Pan Am (January 1991), Midway (March 1991), America West (June 1991), and TWA (January 1992). We focus primarily on the four largest of these, as measured by the number of affected domestic routes: Eastern, Continental, America West, and TWA. We find little evidence that bankruptcy per se affects an airline's pricing behavior, although financial distress that culminates in a bankruptcy filing appears to be associated with somewhat lower prices by the distressed carrier. Among the four major bankruptcies, only one airline - Eastern - appears to have significantly reduced its prices subsequent to filing for Chapter 11, and this change may be confounded with the effects of a contemporaneous strike against the airline. We find no evidence that carriers competing with bankrupt airlines cut their prices on overlapping routes subsequent to a bankruptcy filing, even for the Eastern bankruptcy.

2 See Chevalier, 1994, Chevalier and Scharfstein, 1995, and Kovenock and Phillips, 1995, for examples. 
The analysis in this paper is based on fares recorded in the Department of Transportation's 10\% ticket sample (Databank 1A) for the 26 quarters from 1987:1 through 1993:2. ${ }^{3}$ We first detail the pricing behavior of bankrupt airlines and their rivals for each of the four major bankruptcy events. Regression analysis of price changes for the full set of bankruptcies follows.

\section{Pricing Behavior Around Major Bankruptcies}

Figures $1(\mathrm{a}-\mathrm{d})$ present price trends around the four major airline bankruptcies. For each quarter, we compare the airline's sampled ticket prices to the average price for all domestic tickets on routes in the same 100-mile distance block. A value of zero for this "normalized price" reflects fares equal to the (distance-adjusted) overall domestic average price for that quarter. The solid lines in each figure trace the normalized prices for the bankrupt carriers; the dashed lines trace the normalized prices averaged across all non-bankrupt competitors present on the same routes. The bold vertical line indicates the quarter in which the bankruptcy filing occurred.

3 Details of the dataset construction are available from the authors, and are virtually the same as those described in Severin Borenstein and Nancy Rose (1994). A routes was included only if there were at least 90 passengers recorded in each of the quarters analyzed. 
Looking first at the effect of a bankruptcy filing on an airline's own pricing behavior, we note that only Eastern exhibits a marked change in pricing patterns subsequent to its bankruptcy filing. Prior to its March 1989 bankruptcy announcement, Eastern's normalized prices were stable at about $5 \%$ less than industry averages. The decline in its prices after bankruptcy was large (dropping to $15 \%$ to $25 \%$ below industry average fares) and apparently permanent, although this may confound bankruptcy effects with those of a labor strike during the same period. ${ }^{4}$ This stands in contrast to the three other major bankruptcies we analyze. Continental, TWA and America West all appear to have reduced fares relative to previous trends about 6 months before their bankruptcy filings; these returned to trend within 6 months for TWA, and within a year for America West. Continental fares continued to decline relative to industry average fares through the end of our sample period. With the exception of Eastern, these figures provide little evidence of permanent price changes induced by the bankruptcy filing, and suggest that financial distress rather than bankruptcy per se may be responsible for observed

4 The Eastern strike in the second quarter of 1989 virtually shut down the airline and created significant negative press coverage. We cannot distinguish Eastern's change in pricing strategy around the bankruptcy from the effects of this strike. 
changes in an airline's price preferences.

The pricing behavior of non-bankrupt carriers on routes served by each bankrupt firm is represented by the dashed lines in figures $1(\mathrm{a}-\mathrm{d}) .{ }^{5}$ These do not support the contention that bankrupt airlines have forced down the prices of their competitors. For all four major bankruptcy events, competitors raised normalized prices in the quarter their rival declared bankruptcy; in 3 of the 4 cases, competitors' prices increased further in the quarter following the bankruptcy filing.

While these figures provide a convenient summary of relative price trends, they do not control for changes in the mix of routes over time. Route changes could pose a particular problem for this analysis, since the financially distressed airlines tend to exit routes completely or drop below the $5 \%$ route share threshold we use to denote routes on which a carrier is "active". We therefore next calculate average changes in distance-adjusted normalized prices for the a matched set of routes. ${ }^{6}$ Table 1 reports these results for the bankrupt air-

5 All tickets of non-bankrupt carriers on a route are included in these calculations if the bankrupt carrier has at least a $10 \%$ share of traffic on the route during the quarter.

6 The normalization is now relative to prices of non-bankrupt carriers on routes in the same 100-mile distance category that have no bankrupt (or soon to be bankrupt) carrier present. This approach still does not adjust for changes in "traffic mix," such as decreases in 
lines. The first row indicates the level of normalized prices two quarters before the bankruptcy filing; the subsequent rows report changes in prices relative to this benchmark over the following four quarters. ${ }^{7}$ The number of routes used in each price calculation are bracketed.

The Eastern column, for example, shows that on the 744 Eastern routes in the third quarter of 1988 (1988:3, two quarters before Eastern filed for bankruptcy), Eastern's prices were $0.9 \%$ below industry average, controlling for distance. Eastern's normalized prices in 1989:1, the quarter it filed for bankruptcy protection, had increased by $1.7 \%$ for the 593 routes on which it was still active. Data on prices in the quarter immediately following the bankruptcy filing are not very informative, since Eastern virtually shut down in 1989:2 (it remained active on only 22 routes). By 1989:3, however, Eastern had returned to significant operations (with 564 active routes), and its nor-

average yield for bankrupt carriers due to a decline in the proportion of higher fare business travelers. For a carrier in bankruptcy, this effect will lower the average price reported if, as is often suggested, business travelers are the first to abandon financially distressed airlines. Similarly, this effect could generate increased average prices for competitors of a bankrupt airline as a result of a "richer" traffic mix.

7 To assure that the bankrupt carrier has been a significant competitor in a route, a route is included in the analysis if the bankrupt carrier has at least a $10 \%$ route share two quarters before the quarter in which it declares bankruptcy. We calculate price changes on the route whenever the bankrupt carrier has at least a $5 \%$ route share. 
Table 1

Average Price Changes of Chapter 11 Airlines

Airline Eastern Continental Amer West TWA

$\begin{array}{lcccc}\text { Relative Price at t-2 } & -0.009 & +0.089 & -0.306 & -0.054 \\ & {[744]} & {[679]} & {[284]} & {[419]} \\ \text { Change t-2 to t-1 } & +0.031 & -0.050 & -0.118 & -0.043 \\ & (0.004) & (0.004) & (0.009) & (0.005) \\ & {[665]} & {[674]} & {[278]} & {[416]} \\ \text { Change t-2 to } t & +0.017 & -0.065 & -0.037 & -0.053 \\ & (0.005) & (0.005) & (0.009) & (0.008) \\ & {[593]} & {[657]} & {[259]} & {[412]} \\ \text { Change t-2 to t+1 } & -0.223 & +0.002 & +0.034 & -0.043 \\ & (0.041) & (0.007) & (0.010) & (0.010) \\ & {[22]} & {[659]} & {[257]} & {[407]} \\ \text { Change t-2 to t+2 } & -0.169 & -0.012 & +0.048 & -0.000 \\ & (0.007) & (0.006) & (0.015) & (0.011) \\ & {[564]} & {[657]} & {[241]} & {[380]}\end{array}$

Standard error of average in parentheses.

Number of markets included in brackets.

malized prices were $16.9 \%$ lower than they had been a year earlier. While Eastern substantially lowered its prices subsequent to its bankruptcy filing, this is not true of the three other major bankruptcies. Continental, American West, and TWA prices appear to have declined prior to bankruptcy, but these declines were largely offset in later quarters. For these three airlines, prices were nearly as high or higher two quarters following bankruptcy as they had been two quarters prior to the bankruptcy filing. 
Table 2

Price Changes of Competitors of Chapter 11 Airlines

Airline Eastern Continental Amer West TWA

Relative Price at t-2 $+0.021 \quad-0.009 \quad-0.363 \quad-0.067$

$[739] \quad[645] \quad[261] \quad[403]$

$\begin{array}{ccccc}\text { Change } t-2 \text { to } \mathrm{t}-1 & +0.001 & +0.010 & -0.129 & +0.015 \\ & (0.003) & (0.003) & (0.015) & (0.004) \\ {[658]} & {[633]} & {[251]} & {[399]}\end{array}$

$\begin{array}{lllll}\text { Change } \mathrm{t}-2 \text { to } \mathrm{t} & +0.027 & -0.009 & -0.018 & +0.043\end{array}$

$\begin{array}{llll}(0.004) & (0.005) & (0.009) & (0.008)\end{array}$

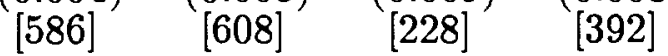

$\begin{array}{lllll}\text { Change } t-2 \text { to } t+1 & -0.020 & +0.024 & +0.057 & +0.007\end{array}$

$\begin{array}{llll}(0.023) & (0.007) & (0.010) & (0.007)\end{array}$

$[21] \quad[608] \quad[222] \quad[387]$

Change $t-2$ to $t+2 \quad+0.071+0.006+0.020+0.005$

$\begin{array}{llll}(0.005) & (0.007) & (0.010) & (0.009)\end{array}$

$\left[\begin{array}{lll}{[561]} & {[602]} & {[207]}\end{array}\right]$

Standard error of average in parentheses.

Number of markets included in brackets.

Table 2 presents the results of this analysis for rivals of each bankrupt airline. ${ }^{8}$ The Continental column, for example, indicates that on the 602 routes on which Continental was still active and faced at least one significant competitor in 1991:2 (two periods after declaring bankruptcy), passenger-weighted average prices of competitors had risen by $0.6 \%$ over the pre-

8 The number of routes in this table are a subset of those in table 1 , since for some of the routes the bankrupt carrier has no significant ( $5 \%$ minimum share) competitor. 
vious four quarters, relative to routes on which no bankrupt carriers were present. Overall, competitors' prices do not tend to decline subsequent to bankruptcy, although America West's rivals (of which Southwest Airlines is most significant) appear to have matched its price cut just prior to its bankruptcy filing. Within two quarters following each bankruptcy filing, competitors prices are about as high (for Continental and TWA) or higher (for Eastern and America West) than they were two quarters prior to the bankruptcy filing. As in the figures presented earlier, the evidence does not support the claim that bankrupt airlines have forced competitors to lower their prices.

These analyses have the prices across all rivals, but theoretical models and some popular accounts suggest that price responses might differ. Models of predatory behavior, for example, suggest that financially healthy ("deep pocket") carriers are more likely to undertake aggressive pricing against weaker rivals. Similarly, executives at some airlines have been more outspoken than others in blaming the industry's financial difficulties on the behavior of financially weak carriers. Table 3 reproduces the last row of Table 2 individually for each of the six largest U.S. airlines that have not entered Chapter 11 since deregulation. American Airlines, probably the most vocal critic of airlines operating under Chapter 11 protection, has 
Table 3

Average Price Changes of Individual

Competitors Over $[-2,+2]$ Window

Bankrupt Airline

Eastern Continental Amer West TWA

\section{Competitor}

American

$$
\begin{array}{cccc}
+0.090 & +0.037 & -0.051 & +0.027 \\
(0.015) & (0.009) & (0.012) & (0.014) \\
{[205]} & {[421]} & {[119]} & {[294]}
\end{array}
$$

Delta

$$
\begin{array}{cccc}
+0.068 & +0.046 & +0.063 & +0.011 \\
(0.005) & (0.009) & (0.021) & (0.012) \\
{[452]} & {[327]} & {[98]} & {[181]}
\end{array}
$$

Northwest

Southwest

$$
\begin{array}{cccc}
+0.105 & -0.018 & +0.368 & +0.007 \\
(0.023) & (0.021) & (0.035) & (0.025) \\
{[71]} & {[114]} & {[30]} & {[123]}
\end{array}
$$

$\begin{array}{ccccc} & & (0.019) & (0.011) & (0.026) \\ \text { United } & {[1]} & {[68]} & {[44]} & {[32]} \\ & -0.014 & -0.082 & -0.039 & +0.019 \\ & (0.019) & (0.009) & (0.013) & (0.014) \\ \text { USAir } & {[48]} & {[252]} & {[120]} & {[184]} \\ & +0.112 & +0.072 & +0.020 & +0.035 \\ & (0.012) & (0.014) & (0.041) & (0.022) \\ & {[89]} & {[134]} & {[19]} & {[88]}\end{array}$

Standard error of average in parentheses.

Number of markets included in brackets.

raised its post-bankruptcy prices relative to industry norms in 3 of the 4 bankruptcies, the 3 cases in which American overlapped on the most routes. USAir, the financially weakest of 
the major airlines that have not sought Chapter 11 protection, raised its prices in response to all 4 bankruptcies, although the average increase is significant in only 2 of these cases. Only United shows a significant price cut in response to more than one of the four bankruptcies, and Delta, one of the financially strongest carriers during this period, exhibits consistently positive price responses. Overall, there appears to be no relationship between financial health and price responses to rivals' bankruptcies.

A final possibility we investigate is whether bankrupt airlines harm competitors by increasing market share through lower prices, service improvements, or special non-price promotions. We first use matched-route analysis similar to the approach used to analyze fares in the previous tables. ${ }^{9}$ Table 4 presents these route average market shares from 2 quarters before through 2 quarters after the carrier files for Chapter 11 protection. These averages are weighted by market size, but the results are very similar if the markets are equally weighted.

In all four of the major bankruptcies, the filing carrier's average market share on routes it continues to serve with a

9 In this case, however, we use a consistent market share cutoff of $10 \%$ for inclusion of a route in order to avoid a selection bias that would result if the inclusion criterion in period $t-2$ were different from the inclusion criterion in later periods. 
Table 4

Average Market Share Changes of Chapter 11 Airlines

Airline Eastern Continental Amer West TWA

$\begin{array}{lllll}\text { Average Share at t-2 } & 0.352 & 0.409 & 0.432 & 0.329 \\ & {[744]} & {[679]} & {[284]} & {[419]}\end{array}$

Change t-2 to t-1 $-0.026+0.019 \quad-0.016+0.028$

$\begin{array}{llll}(0.003) & (0.002) & (0.005) & (0.004)\end{array}$

$[599] \quad[626] \quad[272] \quad[388]$

Change $\mathrm{t}-2$ to $\mathrm{t}$

$\begin{array}{llll}-0.116 & -0.009 & -0.011 & +0.016 \\ (0.004) & (0.003) & (0.006) & (0.006) \\ {[438]} & {[572]} & {[256]} & {[381]}\end{array}$

Change $t-2$ to $t+1$

-0.289
$(0.032)$

$-0.012$

$-0.046 \quad-0.017$

$\left[\begin{array}{llll}12] & {[560]} & {[240]} & {[339]}\end{array}\right.$

Change $t-2$ to $t+2$

$\begin{array}{llll}-0.120 & -0.003 & -0.052 & -0.029 \\ (0.008) & (0.004) & (0.008) & (0.007) \\ {[453]} & {[586]} & {[231]} & {[319]}\end{array}$

Standard error of average in parentheses.

Number of markets included in brackets.

$10 \%$ minimum route share threshold used in all periods.

(minimum 10\% share) either remains about constant, in the case of Continental, or declines over the bankruptcy period. For example, two quarters before its bankruptcy declaration, Continental was active on 679 routes, carrying an average of $40.9 \%$ of the passengers. Two quarters after its bankruptcy declaration, Continental had dropped below a $10 \%$ share on 93 of those routes, and its market share on the remaining 586 declined by an average of $0.3 \%$. Eastern, America West, and 
Table 5

Aggregate Market Share of Chapter 11

Airlines in All Relevant Markets
Airline
Eastern Continental Amer West TWA

Share at $\mathrm{t}-2$

0.158

0.117

0.165

0.063

Share at $\mathrm{t}-1$

0.131

0.125

0.169

0.072

Share at $\mathrm{t}$

0.096

0.114

0.170

0.076

Share at $\mathrm{t}+1$

0.014

0.112

0.162

0.068

Share at $\mathrm{t}+2$

0.063

0.123

0.153

0.063

Number of Markets

2263

3053

850

2225

TWA all a higher proportion of their original routes than did

Continental and experienced more substantial declines in market share on routes they continued to serve subsequent to their bankruptcy filings.

To investigate whether airlines declaring bankruptcy harm competitors by entering new routes, we examine the bankrupt carrier's share of traffic on all "relevant" routes, defined as any route on which the bankrupt carrier had passengers in any quarter of the $[-2,+2]$ window. Table 5 reports the carrier's share of all traffic on this set of routes in each of the quarters. ${ }^{10}$

10 These calculations include all routes on which the bankrupt carrier had a minimum $1 \%$ market share in any of the quarters, regardless of route size. The computed shares are for all passengers on these routes, however, so a very small route has very little infuence on the 
As expected, Eastern's share drops substantially around the bankruptcy declaration. For the other three airlines, share rises just prior to declaring bankruptcy, consistent with the price cuts that they carry out at that time, but then declines after entering Chapter 11. Overall, Continental's share rises slightly (0.6 percentage points) from $t-2$ to $t+2$, TWA's is unchanged, and America West's share falls slightly (1.2 percentage points). Thus, although competitors of bankrupt airlines maintain or increase their prices subsequent to these bankruptcy filings, competitors' market shares appear to increase or remain about constant.

\section{Econometric Analysis of Bankruptcy Effects}

In this section, we report estimates from an econometric model of airline prices, using data on all 7 bankruptcy filings during our sample period of 1988:1 through 1992:4. We model the quarter-to-quarter change in log average price for an airline on a given route as a function of: current and one-period lagged changes in the passenger-based Herfindahl index, to control for changes in market structure; the lagged change in the log price for the airline-route, to control for the substantial negative serial correlation in price changes; fixed time effects, to control

calculation. 
for general airline price movements over time; and a set of bankruptcy measures described below. The model implicitly assumes that exogenous changes in the remaining variables typically included in cross-sectional models of airline price levels such as airport congestion, market density, network interconnectedness, and airport dominance - are sufficiently small that they can be excluded from the specification.

We include two sets of indicator variables designed to capture the effects of impending or recently declared Chapter 11 bankruptcy. The first set measures the average change in price for a bankrupt airline; the second measures the average change in price for non-bankrupt airlines on routes with a nearbankrupt or bankrupt competitor. We scale these variables so that their coefficients reflect price changes over 4 three-month periods: 180 to 90 days and 90 to 0 days before a bankruptcy filing, and 0 to 90 days and 90 to 180 days after a bankruptcy filing. ${ }^{11}$ The sum of the price changes over these four periods

11 The first set of variables indicate bankruptcy status for the observed carrier. We define $B A N K R U P T_{-2}$ as the mean within a quarter of a dummy variable that is zero until 180 days before the observed carrier declares bankruptcy and one thereafter. Thus, if an airline declared bankruptcy on July 31 , one-third of the way through the third quarter of the year, $B A N K R U P T_{-2}$ would take on the value $2 / 3$ in the first quarter of that year and 1 for all subsequent quarters. Similar variables are defined for the periods 90 days before, 90 days following, and 180 days following the bankruptcy filing. Changes in these four variables from the previous quar- 
indicates the net change in price during the window beginning 6 months before and ending 6 months after the date of Chapter 11 filing. None of the airlines in our sample exit Chapter 11 during our observation period, although bankrupt airlines do exit routes or drop below the $10 \%$ share threshold used in the regression analysis.

We estimate the model by ordinary least squares using the 1777 routes for which we observed at least 300 passengers during each quarter from 88:1 through 92:4. The standard errors are adjusted for heteroskedasticity and contemporaneous correlation of residuals across carriers on the same route. Unlike the figures and previous tables, observations are not weighted by the number of passengers in this regression as this would be likely to induce heteroskedasticity.

The results in table 6 suggest that airlines that file for bankruptcy protection cut their prices 90 to 180 days before filing for Chapter 11 , by an average of $5.6 \%$, and maintain this lower price level over the subsequent nine months. As in the earlier tables, there is no indication of substantial changes

ter, $\triangle B A N K R U P T_{i}, \quad i=-2,-1,1,2$, are included in the regression. The second set of variables indicate the bankruptcy status of other carriers on the observed route. For airlines not in or within two quarters of entering Chapter 11, RTBANKRUPT $T_{i}$ measures the presence on a route of another carrier with non-zero values of $B A N K R U P T_{i}$. The $\triangle R T B A N K R U P T_{i}, \quad i=-2,-1,1,2$, are included in the regression. 
Table 6

Estimated Price Changes of

Bankrupt Airlines and Competitors

Dependent Var: DLPRICE ( $\left.=\ln P R I C E_{t}-\ln P R I C E_{t-1}\right)$

Number of Observations: $63671 \quad R^{2}=0.36$

$\operatorname{DLPRICE}_{t-1}$

HERFINDAHL $_{t}$

HERFINDAHL $_{t-1}$

Estimated Price Change:

90-180 days before Chap 11

0-90 days before Chap 11

0-90 days after Chap 11

90-180 days after Chap 11

Change over $[-180,+180]$ days

\section{Bankrupt}

Airline Competitors

$\begin{array}{ll}-0.056 & -0.020 \\ (0.005) & (0.004)\end{array}$

$-0.004$

$(0.006)$

$+0.019$

$(0.005)$

$-0.004$

$(0.007)$

$+0.008$

$(0.006)$

$+0.008$

$(0.006)$

$+0.004$

$(0.005)$

$-0.055$

$(0.010)$
$+0.011$

$(0.003)$

Huber-adjusted standard errors in parentheses.

Fixed effects for each quarter not reported.

in pricing behavior following the bankruptcy filing. Competitors exhibit little price response to this behavior. The results suggest modest $(2 \%)$ price declines by competitors when the 
to-be-bankrupt carrier cuts its prices, but this appears to be more than offset by price increases over the subsequent months. The net change in prices over the year-long window around the bankruptcy announcement is $-5.5 \%$ for the bankrupt carrier and $+1.1 \%$ for its competitors, each statistically different from zero. $^{12}$

Bankruptcy filing is itself endogenous, an issue that we have not addressed in this analysis. This raises questions about the causality of the bankruptcy-pricing correlation we observe. The low prices that appear to precede a bankruptcy filing may themselves have induced that filing, or may be a profitmaximizing response to some exogenous shock, omitted from the model, that contributes to financial decline. The possible endogeneity of bankruptcy is unlikely, however, to change the conclusion that competitors do not respond to a bankrupt airline by lowering price. Failing to model the bankruptcy decision seems most likely to bias downward the estimates of competitors' price changes in our model, since low competitors'

12 The dataset used for this regression required a $10 \%$ minimum route share for a route/carrier/quarter observation to be included. Using a $5 \%$ minimum share, the net price change of the bankrupt carrier is estimated to be $\mathbf{+ 5 . 8 \%}$ and the net price change of competitors is $-0.6 \%$, each statistically different from zero. We also estimated these effects including carrier fixed effects and fixed effects for each 100mile haul length within each quarter. Inclusion of these variables had almost no effect on the parameters of interest. 
prices are more likely to induce financial distress than are high competitors' prices.

\section{Conclusion}

The behavior of firms in financial distress is of growing interest to both academics and public policy makers. In the airline industry, many participants and observers have accused firms under Chapter 11 bankruptcy of pricing in a manner destructive to their competitors as well as to themselves. Our analysis indicates that, with the notable exception of Eastern, bankrupt airlines have changed their prices only modestly around the time of entering Chapter 11, with an average decline of about $5.5 \%$ overall. Such a price cut may be neither destructive nor myopic, but rather a rational business response to the reduced reputation that may surround an airline in financial distress. This interpretation is supported by the evidence that competitors do not lower their average prices in response to price cutting by bankrupt airlines, and that bankrupt airlines do not gain market share despite their price cuts. 


\section{REFERENCES}

Borenstein, Severin and Nancy L. Rose, "Competition and Price Dispersion in the U.S. Airline Industry." Journal of Political Economy, August 1994 102(4), pp. 653-683.

Chevalier, Judith, "Capital Structure and Product Market Competition: An Empirical Study of Supermarket Pricing," mimeo, University of Chicago, September, 1994.

Chevalier, Judith and David Scharfstein, "Capital Market Imperfections and Countercyclical Markups: Theory and Evidence," mimeo, University of Chicago, January 1995.

Kovenock, Daniel and Gordon Phillips, "Capital Structure and Product Market Rivalry: An Examination of Plant Expansion and Closing Decisions," mimeo, Purdue University, January 1995.

The National Commission to Ensure a Strong Competitive Airline Industry, "Change, Challenge and Competition: A Report to the President and Congress," Washington D.C.: U.S Government Printing Office, August 1993. 

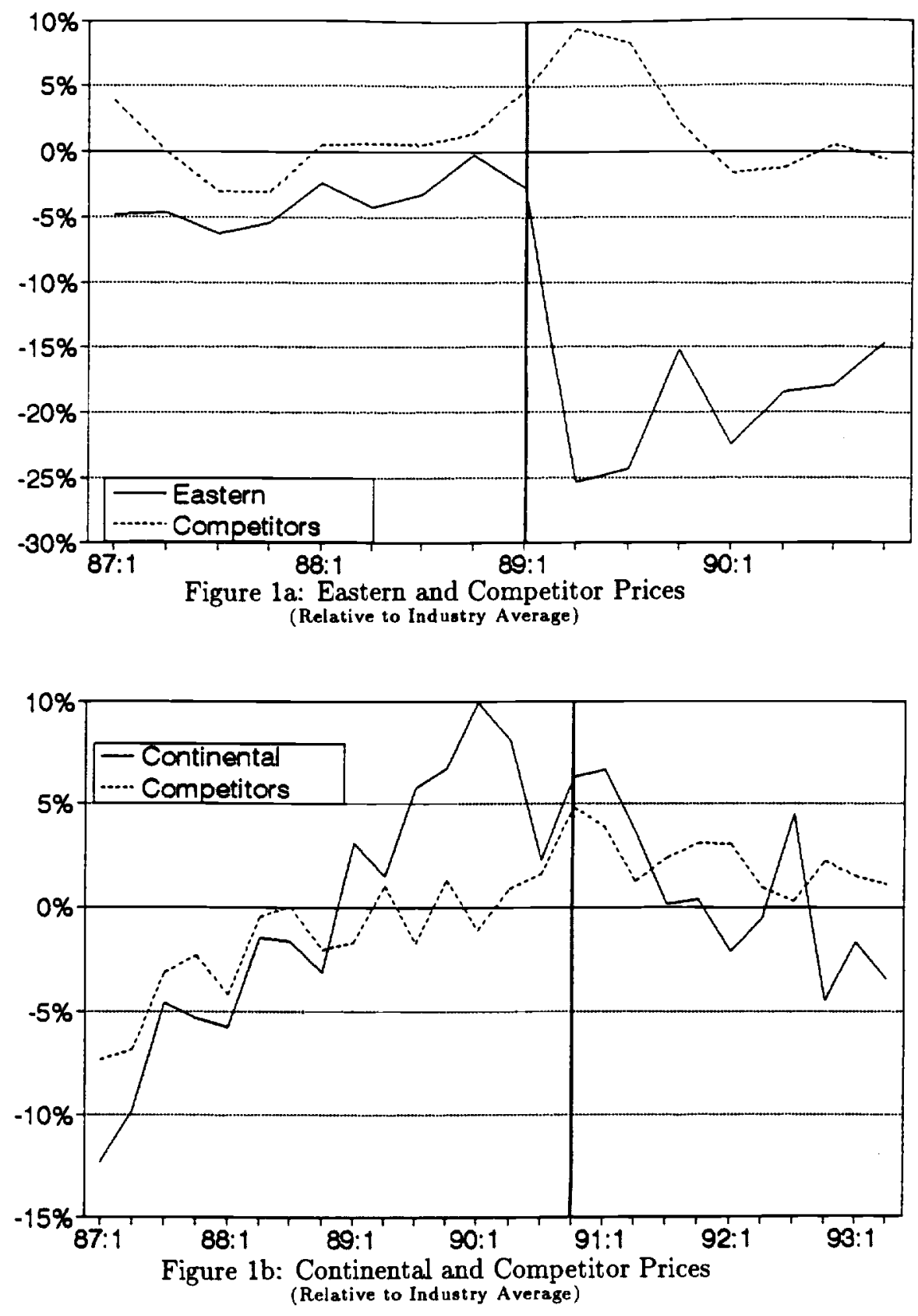


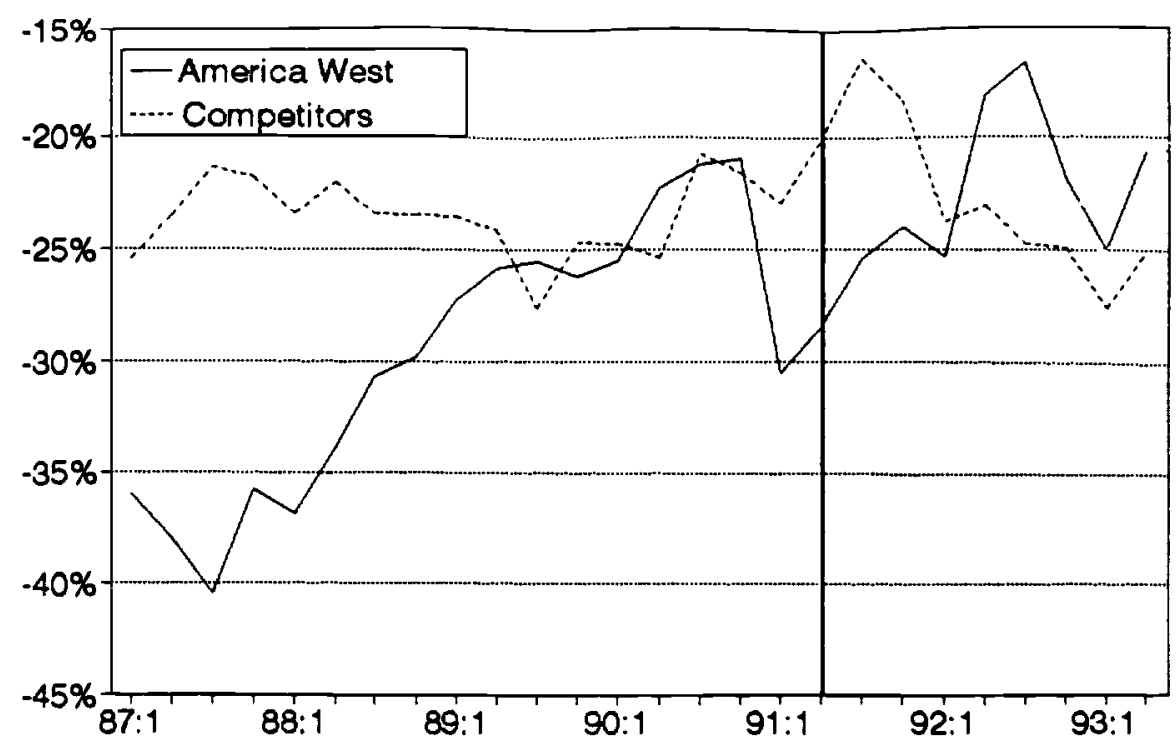

Figure 1c: America West and Competitor Prices

(Relative to Industry Average)

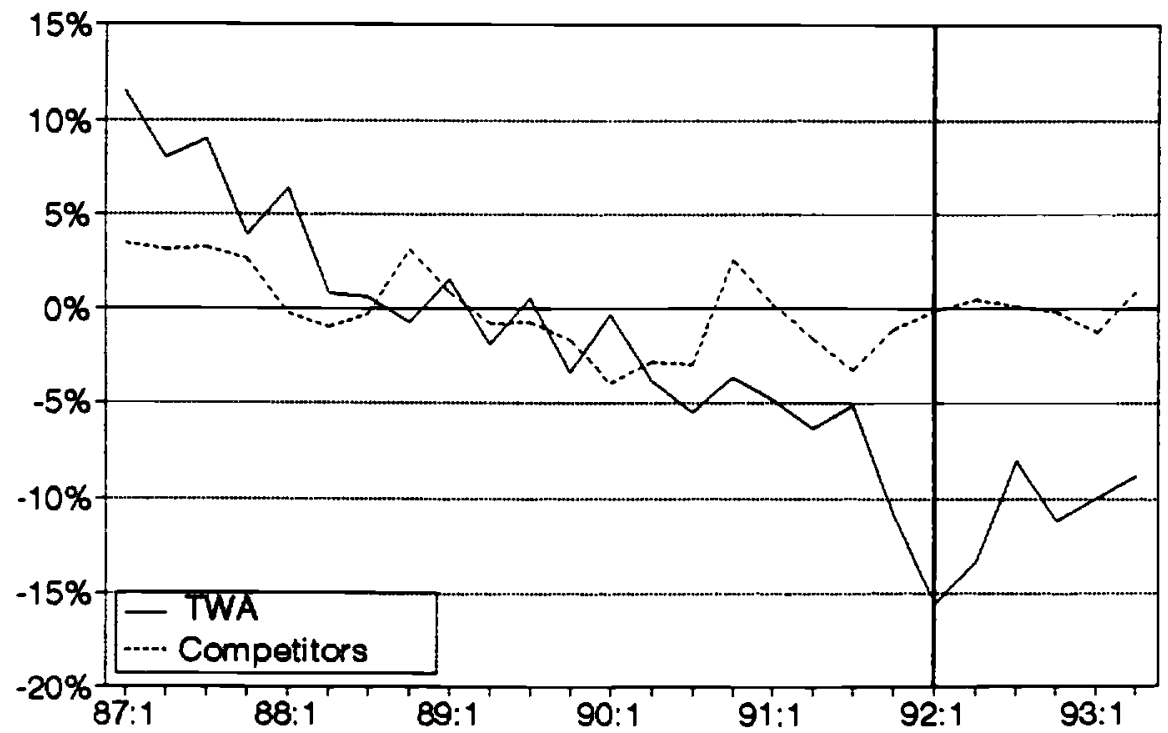

Figure 1d: TWA and Competitor Prices (Relative to Industry Average) 